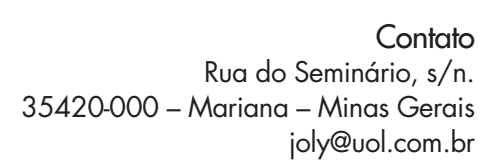

Contato

Rua do Seminário, s/n.

35420-000 - Mariana - Minas Gerais

joly@uol.com.br

\section{LIBERDADE E ESCRAVIDÃO NO PENSAMENTO ESTOICO ROMANO: UMA LEITURA DA CONSOLATIO AD POLYBIUM, DE SÊNECA*}

\author{
Fábio Duarte Joly** \\ Universidade Federal de Ouro Preto \\ Mariana - Minas Gerais - Brasil
}

\title{
Resumo
}

A Consolatio ad Polybium, escrita por Sêneca durante seu exílio na Córsega e endereçada a Políbio, liberto imperial de Cláudio, tem sido interpretada pela historiografia moderna sob duas perspectivas. Por um lado, é discutida sua estrutura literária, tendo em vista o gênero da consolação na Antiguidade. Por outro lado, análises históricas buscam perceber como o filósofo apresenta o imperador Cláudio nos quadros de uma reflexão estoica sobre o poder imperial. Embora ambas as análises sejam pertinentes, o objetivo deste artigo volta-se para o próprio retrato do liberto por Sêneca, e como este se conforma a determinado pensamento estoico sobre a escravidão em que o liberto é retratado como inelutavelmente preso ao passado servil, uma vez que sua forma de pensar e agir não consegue desvencilhar-se do período de escravidão.

\section{Palavras-chave}

Estoicismo - Sêneca - escravidão.

Uma versão preliminar deste texto foi apresentada no II Colóquio LEIR-UFOP \& Universidade de Coimbra: A ação do tempo na modelação dos retratos históricos, realizado na Universidade Federal de Ouro Preto, em Mariana (MG), entre 2 e 3 de junho de 2016.

* Doutor em História pelo Programa de pós-graduação em História Econômica do Departamento de História da Faculdade de Filosofia, Letras e Ciências Humanas da Universidade de São Paulo. Membro do Laboratório de Estudos sobre o Império Romano (LEIR) e bolsista de produtividade do Conselho Nacional de Desenvolvimento Científico e Tecnológico (CNPq). Professor associado de História Antiga no Departamento de História/UFOP. 


\author{
Contact \\ Rua do Seminário, s/n. \\ 35420-000 - Mariana - Minas Gerais \\ joly@uol.com.br
}

\section{FREEDOM AND}

SLAVERY IN ROMAN

STOIC THOUGHT:

\section{A READING \\ OF SENECA'S \\ CONSOLATIO AD \\ POLYBIUM}

\author{
Fábio Duarte Joly**
}

Universidade Federal de Ouro Preto

Mariana - Minas Gerais - Brazil

\begin{abstract}
The Consolatio ad Polybium, written by Seneca during his exile in Corsica and addressed to Polybius, an imperial freedman of Claudius, has been interpreted by modern historiography from two perspectives. On the one hand, its literary structure is analyzed, taking the consolatio as a literary genre in Antiquity. On the other hand, historical approaches to this work try to understand how the philosopher presents the Emperor Claudius according to a Stoic reflection on imperial power. Although both types of studies are relevant, the purpose of this article is the very image of Polybius drawn by Seneca. The argument is that this image relates to a particular Stoic view of slavery, in which the freedman is portrayed as inextricably tied to his servile past.
\end{abstract}

\title{
Keywords
}

Stoicism - Seneca - slavery. 


\section{Introdução: Sêneca, a escravidão e o estoicismo}

Os estudos dedicados às ideias greco-romanas sobre escravidão normalmente analisam o papel do estoicismo a partir de sua contraposição à teoria aristotélica da escravidão natural. Como Peter Garnsey sintetiza, os estoicos

não mais se perguntavam, como Aristóteles era obrigado a fazer, como a forma mais pura de exploração legal de algumas pessoas por outras poderia ser justificada, mas como os homens poderiam libertar suas almas da opressão pelas paixões e emoções, e pautar seus comportamentos e atitudes morais de acordo com uma lei superior àquela humana, a lei da natureza. ${ }^{1}$

Nesse sentido, os escritos de Sêneca são usualmente citados para afirmar a preponderância, em seu pensamento, da escravidão moral sobre a escravidão legal, no que seria uma tentativa de rejeitar a teoria da escravidão natural. A escravidão seria obra da Fortuna, podendo recair sobre quaisquer indivíduos; o importante seria a liberdade da alma, o desprendimento dos bens terrenos e a anulação do medo da morte. ${ }^{2}$

Esse procedimento de análise das ideias estoicas sobre escravidão, circunscrito ao âmbito filosófico, acaba por deixar em segundo plano a dimensão social dessas ideias, de modo que é cabível a afirmação de Runar Thorsteinsson de que

não há qualquer razão sustentável para suspeitar que os estoicos estivessem vagamente interessados em questões sociais ou que seu interesse fosse superficial. Pelo contrário, vemos nos textos dos estoicos romanos uma muito forte e consistente preocupação com questões relacionadas a temas sociais. Isso não deveria nos surpreender visto que a dimensão social é meramente uma consequência natural da doutrina estoica da humanidade universal. ${ }^{3}$

Essa observação é diretamente aplicável a uma reavaliação do estoicismo de Sêneca, pois predominam estudos sobre o conteúdo filosófico de seus conceitos de liberdade e escravidão, evitando-se tentativas de relacionar tais conceitos com a visão senequiana das relações escravistas em Roma.

\footnotetext{
1 GARNSEY, Peter. Ideas of slavery from Aristotle to Augustine. Cambridge: Cambridge University Press, 1996, p. 150.

2 GRIFFIN, Miriam. Seneca: a philosopher in politics. Oxford: Oxford University Press, 1976, p. 257.

3 THORSTEINSSON, Runar. Roman Christianity and Roman Stoicism: a comparative study of ancient morality. Cambridge: Cambridge University Press, 2010, p. 177.
} 
Esta tendência é particularmente visível, por exemplo, na crítica que Brad Inwood dirige ao estudo de Matthew Roller acerca da representação das relações entre imperador e aristocracia sob os Júlio-Cláudios. Para Roller seria equivocado referir-se à libertas como uma "ideia política" ou com um "significado político" na cultura romana. Isso sugeriria que o termo designaria uma categoria coerente do pensamento político romano, independentemente de sua função como uma categoria de status social e sua imbricação na instituição da escravidão-mercadoria. ${ }^{4}$

Assim, libertas e servitus, ao caracterizarem as relações entre imperador e aristocracia, apenas reiterariam estereótipos inerentes à condição do escravo. Quando Roller examina a obra de Sêneca, propõe-se então a sublinhar aquelas passagens em que ocorreria uma justaposição do domínio filosófico de referência, dos termos "escravidão" e "liberdade", àquele domínio literalmente associado à escravidão-mercadoria. ${ }^{5}$ Pelo contrário, para Inwood, o importante seria ir além deste aspecto do estoicismo de Sêneca e sugerir que suas reflexões sobre liberdade e autonomia abririam novas fronteiras no interior da própria filosofia estoica. ${ }^{6}$ Seguindo essa ótica, há autores que enfatizam, por exemplo, como a escravidão é utilizada por Sêneca para descrever o ego, que assume alternadamente os papéis de senhor e escravo em seu discurso filosófico. ${ }^{7}$

Este artigo vincula-se mais à proposta de Roller, mas não tratando a relação do estoicismo com a escravidão em Roma a partir do que seriam características essenciais dessa instituição social, ou, nas palavras do autor, as "condições básicas da existência servil na sociedade romana": a sujeição à violência, compra e venda, separação de familiares e condições precárias de alimentação, vestimenta e moradia. ${ }^{8}$ Parto do princípio de que o estoicismo

${ }^{4}$ ROLLER, Matthew. Constructing Autocracy: Aristocrats and Emperors in Julio-Claudian Rome. Princeton: Princeton University Press, 2001, p. 232.

${ }^{5}$ Ibid., p. 275.

6 INWOOD, Brad. Reading Seneca: Stoic philosophy at Rome. Oxford: Oxford University Press, 2005, p. 304-305.

7 EDWARDS, Catharine. Free yourself!: slavery, freedom and the self in Seneca's letters. In: BARTSCH, Shadi \& WRAY, David (ed.). Seneca and the self. Cambridge: Cambridge University Press, 2009, p. 139-159.

8 ROLLER, Matthew. Constructing Autocracy, op. cit., p. 223. Roller segue Orlando Patterson e sua descrição do escravo como um "morto social". Ver PATTERSON, Orlando. Slavery and social death: a comparative study. Massachusetts: Harvard University Press, 1982. Uma crítica ao essencialismo da abordagem de Patterson encontra-se em MILLER, Joseph. The problem of slavery as history: a global approach. Yale: Yale University Press, 2012. 
senequiano ganha em compreensão se localizado no contexto histórico específico do período Júlio-Cláudio, de Augusto a Nero, quando não apenas os modelos de gestão dos escravos eram objeto de um debate público, mas sobretudo a prática da manumissão e seus desdobramentos chamavam a atenção do imperador e da elite política. ${ }^{9}$

\section{Sêneca e os libertos à luz da política da manumissão sob os Júlio-Cláudios}

O principado de Augusto ocasionou uma ruptura relevante no campo da escravidão, embora em outros domínios tenha representado muito mais uma continuidade. ${ }^{10}$ A legislação augustana rompeu com a associação imediata entre libertas e civitas, comum durante todo o período republicano e citada com aprovação por intelectuais gregos como Dionísio de Halicarnasso. ${ }^{11}$

A Lex Fufia Caninia (2 a.C.) estipulou um número máximo de escravos a serem manumitidos por testamento, determinando que a proporção diminuía à medida que o tamanho da familia aumentava. Em segundo lugar, Augusto introduziu uma nova categoria de libertos, criada pela Lex Junia: os Latini Juniani, que eram livres, mas não cidadãos romanos plenos. Por fim, pela Lex Aelia Sentia, de 4 d.C., fixou-se que o escravo que recebesse a liberdade antes dos trinta anos de idade, ou cujo senhor tivesse menos de vinte anos, não teria direito à plena cidadania, adquirindo o status de Latinus Junianus. Tais libertos podiam adquirir e vender propriedade ou firmar contratos, mas não lhes era permitido o direito romano de conubium e de transmitir

\footnotetext{
9 Para Neville Morley (2011, p. 280), nesse momento da história romana, "a escravidão parece ter se tornado um foco de ansiedades a respeito de mudanças mais amplas na estrutura social, envolvendo a substituição da distinção fundamental entre cidadão e não-cidadão (mesmo se o corpo cidadão fosse então internamente estratificado) por uma sociedade estratificada pela riqueza (em que os direitos políticos às vezes, mas não sempre, determinavam a hierarquia dentro de um grupo específico)". Sobre a escravidão no principado neroniano, ver ANDRÉ, Jean-Marie. L'esclavage sous Néron : statut juridique et condition réelle. In: CROISILLE, Jean-Michel \& FAUCHÈRE, Pierre. Neronia 1977 : Actes du $2^{\circ}$ colloque de la Société Internationale d'Études Néroniennes. Clermont-Ferrand: Adosa, 1982, p. 13-22.

${ }^{10}$ Em sua crítica à dicotomia República/Império na historiografia moderna, Fábio Faversani (2013, p. 108) comenta, por exemplo, que "a construção de um ambiente provincial, a ordenação institucional destes espaços e sua dinâmica econômica e, especialmente, as formas pelas quais as elites provinciais e elites locais se relacionavam através de vínculos de patronato, não têm como um divisor relevante a consolidação de Augusto no poder".

${ }^{11}$ BRIQUEL, Dominique. Petite histoire d'une grande idée : l'ouverture de la citoyenneté aux anciens esclaves, source de la puissance de Rome. Acta Classica, Pretoria, vol. 36, 2000, p. 31-49.
} 
seus bens a herdeiros naturais. Ou seja, não podiam redigir testamento, de modo que, assim como o pecúlio de um escravo, suas posses, ao morrerem, voltavam ao patrono. A mesma Lex Aelia Sentia estabelecia que o escravo que não fosse libertado pelos procedimentos formais - vindicta ou testamento (a manumissio censu desapareceu sob o Império) -, mas apenas pela vontade (voluntas) do senhor, "entre amigos" (inter amicos), também seria considerado

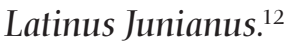

Por meio dessa política houve um reforço do poder senhorial, visto que os senhores agora adquiriam a vantagem de um maior controle sobre seus dependentes. ${ }^{13}$ A par dessas medidas, Augusto também cerceou o direito de associação, ao obrigar os collegia a serem autorizados pelo Senado ou pelo imperador. Reduziu-se, dessa maneira, o poder político da plebe urbana, da qual uma parte considerável era composta por libertos. Como salientou Carlos Galvão-Sobrinho,

o efeito combinado dessas novas políticas foi tornar escravos e libertos ainda mais dependentes de seus senhores e patronos, não apenas para ascensão pessoal, mas para cobrir suas muitas necessidades cotidianas. Após Augusto, as oportunidades para melhora na condição pessoal, mobilidade social e até para associação mútua voltaram-se decisivamente para o contexto "privado" da casa. ${ }^{14}$

Esse quadro geral, a meu ver, é passível de ser utilizado para analisarmos o lugar da escravidão no pensamento estoico romano, pois este é pautado pelo entendimento de que a liberdade cívica adquirida pelo liberto não o torna, de imediato, livre do ponto de vista moral. O liberto, pelo ângulo moral, continuaria escravo, como se não conseguisse romper o vínculo com o senhor. Em outras palavras, o liberto é retratado como inelutavelmente preso ao passado servil, uma vez que sua forma de pensar e agir não conse-

\footnotetext{
12 JOLY, Fábio Duarte. Libertate opus est: escravidão, manumissão e cidadania à época de Nero (54-68 d.C.). Curitiba: Progressiva, 2010, p. 69-70. Para um tratamento das leges Junia, Aelia Sentia e Fufia Caninia, do ponto de vista jurídico, consultar BUCKLAND, William. The Roman law of slavery. Cambridge: Cambridge University Press, 1908, p. 537ss. e 546ss.

${ }^{13}$ GARDNER, Jane. The purpose of the Lex Fufia Caninia. Echos du Monde Classique/Classical Views, Toronto, vol. 35, 1990, p. 29; KOOPS, Egbert. Masters and freedmen: Junian Latins and the struggle for citizenship. In: DE KLEIJN, Gerda \& BENOIST, Stéphane (ed.). Integration in Rome and in the Roman world: proceedings of the Tenth Workshop of the International Network Impact of Empire (Lille, June 23-25, 2011). Leiden: Brill, 2014, p. 115.

${ }^{14}$ GALVÃO-SOBRINHO, Carlos. Feasting the dead together: household burials and the social strategies of slaves and freed persons in the early Principate. In: BELL, Sinclair \& RAMSBY, Teresa (ed.). Free at last!: the impact of freed slaves on the Roman Empire. London: Bristol Classical Press, 2012, p. 145.
} 
gue desvencilhar-se do período de escravidão, como se a alma continuasse escravizada após a libertação do corpo. É uma ótica que se insere nos desdobramentos da legislação augustana e que encontra eco na distinção estoica entre liberdade civil e liberdade moral.

Esse contexto molda a percepção de Sêneca seja dos libertos em geral, seja dos libertos imperiais em específico, pois o filósofo serve-se da figura do liberto para argumentar que a verdadeira liberdade não é aquela que se adquire num ato de manumissão. ${ }^{15} \mathrm{Em}$ suas palavras:

Aquilo que pode fazer de ti um homem de bem existe dentro de ti. Para seres um homem de bem só precisas de uma coisa: a vontade. Em que poderás exercitar melhor a tua vontade do que no esforço para te libertares da escravidão que oprime o gênero humano, essa escravidão a que até os escravos do mais baixo estrato, nascidos, por assim dizer, no meio do lixo, tentam por todos os meios eximir-se? O escravo gasta todas as economias que fez à custa de passar fome para comprar a sua alforria; e tu, que te julgas de nascimento livre, não estás disposto a gastar um centavo para garantires a verdadeira liberdade?! Escusas de olhar para o cofre, que esta liberdade não se compra. Por isso te digo que a "liberdade" a que se referem os registros públicos é uma palavra vã, pois nem os compradores nem os vendedores da alforria a possuem. O bem que é a liberdade terás tu de dá-lo a ti mesmo, de o reclamar a ti mesmo! Liberta-te, para começar, do medo da morte (já que a ideia da morte nos oprime como um jugo, depois do medo da pobreza). ${ }^{16}$

O argumento central desenvolvido pelo filósofo é que a liberdade civil não corresponde à liberdade moral, já que esta última encontra-se na filosofia (estoica), capaz de ensinar os homens a desprezarem os bens terrenos e o temor da própria finitude, da morte, alcançando a posição de sábios, ou seja, de homens que vivem de acordo com a natureza.

O liberto não se situaria jamais nessa categoria, embora Sêneca, por vezes, tome-o como exemplo de que a taxonomia jurídica, que ratifica as desigualdades sociais, não deve ser tomada como parâmetro no julgamento

\footnotetext{
${ }^{15}$ Sobre a apreciação geral de Sêneca sobre os libertos, retomo JOLY, Fábio Duarte. Libertate opus est, op. cit., 2010, p. 212-215.

${ }^{16}$ Sen. Ep., 80.4-5. Tradução de J. Segurado e Campos. No original: "Quidquid facere te potest bonum tecum est. Quid tibi opus est ut sis bonus? Velle. Quid autem melius potes velle quam eripere te huic servituti quae omnes premit, quam mancipia quoque condicionis extremae et in his sordibus nata omni modo exuere conantur? Peculium suum, quod comparaverunt ventre fraudato, pro capite numerant: tu non concupisces quanticumque ad libertatem pervenire, qui te in illa putas natum? Quid ad arcam tuam respicis? Emi non potest. Itaque in tabellas vanum coicitur nomen libertatis, quam nec qui emerunt habent nec qui vendiderunt: tibi des oportet istud bonum, a te petas. Libera te primum metu mortis: illa nobis iugum inponit; deinde metu paupertatis".
} 
de um indivíduo. ${ }^{17}$ Em tal instância, o liberto aparece sob uma luz positiva, como exemplum de promoção social. Numa carta a Lucílio, escreve que

ninguém há cuja origem se não perca na memória dos tempos. Diz Platão que todo rei descende de escravos, que todo escravo é descendente de reis. As diferentes condições sociais foram confundidas por longa série de perturbações, todas a fortuna elevou ou abateu. [...] Desde a primeira origem do mundo até os nossos dias a humanidade percorreu uma série alternada de grandeza e decadência. Um átrio cheio de bustos enegrecidos pelo fumo não faz de ninguém um nobre. Nenhum homem viveu para nos dar glória, nada do que nos precedeu no tempo nos pertence. A alma é o que nos dá a nobreza, uma nobreza a que qualquer um pode aceder, independentemente da sua condição social. Imagina que não és um cavaleiro romano, mas sim um liberto: está na tua mão conseguir que entre gente de origem livre o único homem livre sejas tu. ${ }^{18}$

Por outro lado, a afirmação de que um libertinus deve esforçar-se para ser livre entre os ingenui denota que o ex-escravo ou seus descendentes são "menos livres" do que os indivíduos de pais livres. Os libertos são, portanto, considerados cidadãos de segunda categoria, que não nascem cidadãos, mas compram a cidadania por meio de uma transação financeira. Quando cita certo liberto Calvísio Sabino, o tema da compra de status é realçado; Sêneca escreve que tal indivíduo "tinha os bens de fortuna e a inteligência próprias de um liberto", porque pensava que era possível comprar erudição, adquirindo escravos versados em Hesíodo, em Homero e nos poetas líricos. ${ }^{19}$ Seu exemplo serve para ilustrar a máxima de que "um espírito virtuoso não é coisa que se peça emprestada ou se possa comprar" (bona mens nec commodatur nec emitur) ${ }^{20}$.

Mas é na Consolação a Políbio - cujo personagem central é um liberto imperial - que fica mais claro como o filósofo, no fundo, rebaixa os libertos ao nível de escravos, desconsiderando a alteração de status provocada pela manumissão.

\footnotetext{
${ }^{17}$ Cf. Ep., 31.11 e Ben., 3.18.

${ }^{18}$ Ep. 44.4-6. Tradução de J. Segurado e Campos. No original: "nullius non origo ultra memoriam iacet. Platon ait neminem regem non ex servis esse oriundum, neminem non servum ex regibus. Omnia ista longa varietas miscuit et sursum deorsum fortuna versavit. [...] A primo mundi ortu usque in hoc tempus perduxit nos ex splendidis sordidisque alternata series. Non facit nobilem atrium plenum fumosis imaginibus. Nemo in nostram gloriam vixit nec quod ante nos fuit nostrum est; animus facit nobilem, cui ex quacumque condicione supra fortunam licet surgere. Puta itaque te non equitem Romanum esse sed libertinum; potes hoc consequi, ut solus sis liber inter ingenuos".

${ }^{19}$ Ep. 27.5 .

${ }^{20}$ Ep. 27.8.
} 


\section{O retrato de Políbio por Sêneca: entre a liberdade e a escravidão}

Uma datação provável da Consolação a Políbio situa-se entre o final de 43 e o início de 44 d.C. O motivo da carta é consolar Políbio pela perda de seu irmão, mas o objetivo maior é solicitar uma intercessão junto ao imperador para que este permita que Sêneca volte do exílio, para o qual foi enviado sob a acusação de adultério com Júlia Lívila, irmã de Calígula.

Embora endereçada ao liberto de Cláudio, a obra permite tecer reflexões sobre a construção de três retratos, todos inter-relacionados: um retrato de Sêneca, como emissor; um retrato de Políbio, como destinatário direto; e um retrato do imperador Cláudio, como destinatário indireto. Em decorrência dessa tripartição, vislumbramos nesse pequeno texto senequiano a confluência de elementos de gêneros literários diversos: literatura de exílio, carta consolatória e panegírico. Nesse sentido, o desafio é propor uma análise que equilibre a influência dessas variantes, ou seja, que mostre que cada retrato se constrói em relação aos demais.

Digo isso porque, na bibliografia sobre o Ad Polybium, a tendência é enfatizar ou o retrato de Sêneca ou aquele de Cláudio, de modo que o retrato de Políbio (e também de seu irmão morto) fique em segundo plano. O foco recai assim na relação entre Sêneca e Cláudio, de modo que importaria mais notar como o primeiro constrói uma imagem do segundo para louvar o monarca, ${ }^{21}$ servindo-se do liberto como intermediário para conseguir o fim de seu exílio. "Dissimulação" e "adulação" são termos a que volta e meia se recorre para qualificar essa carta de Sêneca, de modo que, na visão de John Atkinson, os estudiosos ficaram tão preocupados em julgar as intenções de Sêneca de um ponto de vista ético que uma análise propriamente dita do texto ficou em segundo plano. ${ }^{22}$ De fato, análises recentes sobre o texto têm revelado como essa leitura moralista é redutora, pois distancia a obra do conjunto da obra senequiana e de seu conteúdo filosófico-político, bem

\footnotetext{
${ }^{21}$ Nesse sentido, uma série de características positivas de Cláudio são apresentadas (cf. OSGOOD, Josiah. Claudius Caesar: image and power in the Early Roman Empire. Cambridge: Cambridge University Press, 2011, p. 143-144). Em primeiro lugar, Cláudio aparece como responsável pelo mundo inteiro, do qual ele é o centro. Segundo, ao governar seus súditos, Cláudio mostrou-se mais um dispensador de benefícios do que apoiado na força das armas. Terceiro, Cláudio é um deus.

${ }^{22}$ ATKINSON, John. Seneca's Consolatio ad Polybium. Aufstieg und Niedergang der römischen Welt, 2.32.2, 1985, p. 872.
} 
como impede de se atentar para as múltiplas leituras que o texto permite com suas estratégias de persuasão. ${ }^{23}$

Seguindo essa perspectiva, minha ideia é verificar a relação do retrato de Políbio com aqueles de Sêneca e Cláudio, mostrando, por um lado, sua centralidade na narrativa, e, por outro, como ele desvela certa imagem do liberto, associada ao pensamento estoico já mencionado, um tema que, a meu ver, não é desenvolvido em estudos sobre essa carta consolatória.

Vejamos então quem foi Políbio. Sobre este liberto, encontram-se poucas referências na literatura - além de Sêneca, Suetônio e Dião Cássio o mencionam - e não há qualquer registro epigráfico. Paul Weaver sustenta que é provável que Políbio tenha sido manumitido pelo próprio Cláudio antes de 41, visto que já estaria numa posição elevada, a julgar pelo modo como Sêneca se dirige a ele na consolação. No começo do governo de Cláudio, Políbio, de acordo com Sêneca, seria a libellis, responsável pelas petições dirigidas ao imperador. ${ }^{24}$ Já Suetônio menciona sua posição como $a b$ studiis. ${ }^{25}$ Ainda de acordo com Weaver, como o exercício simultâneo dessas funções não era muito comum, é provável que tenha sido sucedido por Calisto como a libellis e depois tornou-se $a b$ studiis. ${ }^{26}$

Políbio não é citado por Tácito como um participante direto, ao lado dos libertos Pallas, Calisto e Narciso, das intrigas dinásticas que marcaram o principado de Cláudio após a morte de Messalina, sua esposa, em 48. No relato taciteano, Narciso fica à frente das ações que culminaram na morte de Messalina. Como resultado final, ganha honrarias, destacando-se dos outros

\footnotetext{
${ }^{25}$ Menciono, em especial, os seguintes trabalhos: ANDRÉ, Carlos Ascenso. Trilhos de evasão: estratégia retórica de Sêneca nas consolações ad Helviam e ad Polybium. Humanitas, Coimbra, vol. 47, 1995, p. 593-615; PIERINI, Rita Degl'Innocenti. Tra Ovidio e Seneca. Bologna: Pàtron Editore, 1990; DOPP, Siegmar. Claudius in Senecas Trostschift an Polybius. In: STROCKA, Volker (ed.). Die Regierungszeit des Kaiser Claudius (41-54 n. Chr.): Umbruch oder Episode? Mainz: Philipp von Zabern, 1994, p. 295-306; FANTHAM, Elaine. Dialogues of displacement: Seneca's consolations to Helvia and Polybius. In: GAERTNER, Jan. (ed.). Writing exile: the discourse of displacement in Greco-Roman Antiquity and beyond. Leiden: Brill, 2007, p. 173-192; GLOYN, Liz. Show me the way to go home: a reconsideration of Seneca's De consolatione ad Polybium. American Journal of Philology, Baltimore, vol. 135, n. 3, 2014, p. 451-480.

${ }^{24}$ Ad Pol. 6.5.

${ }^{25}$ Suet. Cl. 28.

${ }^{26}$ WEAVER, Paul R. C. Repertorium familiae caesarum et libertorum augustorum. Köln: Universität zu Köln, 2005. Disponível em: http://alte-geschichte.phil-fak.uni-koeln.de/500.html. Acesso em: $15 / 02 / 2016$
} 
libertos. ${ }^{27}$ No caso da escolha da nova esposa de Cláudio, Tácito expõe as deliberações entre Pallas, Calisto e Narciso, quando então prevaleceu Agripina, aliada de Pallas. ${ }^{28}$

No resumo bizantino do relato de Dião Cássio, Pallas, Calisto e Narciso têm igualmente uma preeminência, mas é sugerida uma ligação de Políbio com esses três libertos, ainda que esta não seja esclarecida. Nesse relato, os três libertos aparecem atuando em conjunto, inicialmente em acordo com Messalina e depois contrários a ela, em virtude da morte de Políbio, causada por uma falsa acusação da parte de Messalina, que seria sua amante. ${ }^{29}$ Em Suetônio, Políbio aparece também separado do grupo mais poderoso de libertos, exemplificado por Narciso e Pallas. ${ }^{30}$

Portanto, ainda que fosse uma figura próxima ao imperador, sua atuação política não aparece enfatizada pelas fontes. De fato, ao contrário de Pallas, Calisto e Narciso, alvos de críticas constantes da parte de Tácito, Plínio, o Jovem, e Dião Cássio, em apenas um caso Políbio recebe uma menção mais direta, e isto se dá num trecho da História Romana, de Dião Cássio, em que afirma que, embora Cláudio castigasse rigorosamente os libertos dos outros, nada fazia contra os seus. E cita o exemplo de um episódio no teatro, quando um ator pronunciou: “Insuportável é o comerciante de estribo que a fortuna elevou"; Políbio, então, a quem todo o povo tinha lançado os olhos, falou em voz alta: "O mesmo poeta também disse: 'reis tornaram-se aqueles que, anteriormente, eram pastores de cabras'".31

Se esse retrato visa, por um lado, tecer explicitamente uma crítica a Cláudio no tocante ao controle de seus libertos, por outro, aponta, não intencionalmente, uma característica que está presente no Ad Polybium: a referência à cultura literária do liberto. Sêneca, aliás, se dirige ao liberto imperial com um tom cúmplice de literato, como se fosse o diálogo entre dois homens de cultura. ${ }^{32}$ Sobre a ligação de Políbio com as letras, escreve:

\footnotetext{
${ }^{27}$ Tac. Ann. 11.38.6. No original: "[...] decreta Narcisso quaestoria insignia, levissimum fastidii eius, cum super Pallantem et Callistum ageret".

${ }_{28}$ Ann. 12.1.1-3.

${ }^{29}$ D.C. 61.31.2.

${ }^{30} \mathrm{Cl} .28$.

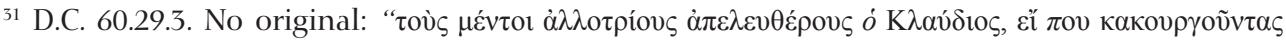

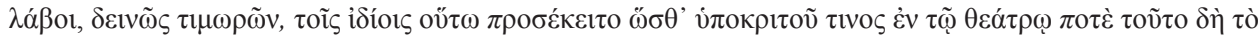

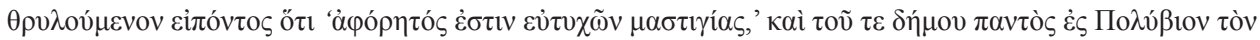

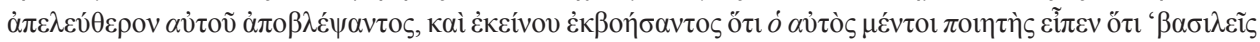

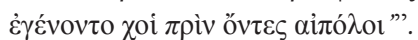

32 PIERINI, Rita Degl'Innocenti. Tra Ovidio e Seneca, op. cit., 1990, p. 115-116.
} 
Assim, não se concebe que alguma vez te permitas deixar os estudos. Então deem paga a ti as tuas letras tão longamente e tão fielmente amadas; então salvem elas a ti, seu mestre e cultor; então, tendo tu desejado dá-los a conhecer a mais pessoas do que a seu público original, passem muito tempo contigo Homero e Virgílio, tão beneméritos do gênero humano quanto foste benemérito deles e de todos; estará seguro o tempo todo o que entregares a eles para ser guardado. ${ }^{33}$

Expressão semelhante encontra-se em Ovídio ${ }^{34}$ ao dirigir-se a Igino, também liberto imperial de Augusto, definindo-o como cultor et antistes doctorum sancte virorum. ${ }^{35}$ Assim como Ovídio buscava obter a tutela de sua obra literária, Sêneca, por meio de Políbio, almeja se aproximar de Cláudio, uma mediação construída pela imagem de uma atividade literária comum - atividade esta que Sêneca, ao final da consolação, mostra que, no seu caso, está afetada pelo exílio, numa passagem que novamente lembra Ovídio:

Isso, como quer que tenha podido, compus com o espírito já desusado e embotado pela longa inação. Se parecer pouco à altura de teu engenho ou pouco remediar tua dor, pensa em quanto não poderia dar-se à consolação alheia aquele cujos males mantêm ocupado, e em quanto não ocorrem facilmente palavras latinas a um homem a quem envolve o vozerio grosseiro dos bárbaros, bruto mesmo para os bárbaros um tanto humanos. ${ }^{36}$

Temos aqui então, nessa autoconsolação de Sêneca, um primeiro nível em que os retratos do filósofo e do liberto se relacionam. A citação da atividade literária, que ambos compartilham, remete, por sua vez, à elaboração de uma junção entre a superação da perda de Políbio e a reintegração do exilado Sêneca, ambas dependendo do imperador.

Nesse contexto, Sêneca procura prescrever um comportamento estoico a Políbio, apresentando formas de conduta para aceitar a morte do irmão.

\footnotetext{
${ }^{33}$ Ad Pol. 8.2. Tradução de Matheus Trevizam e Ana Araújo Grossi Ribeiro. Belo Horizonte: FALE: UFMG, 2007 (doravante usarei esta tradução da consolação).No original: "Itaque non est quod ullum tempus vacare patiaris a studiis: tunc tibi litterae tuae, tam diu ac tam fideliter amatae, gratiam referrant; tunc te illae antistitem et cultorem suum vindicent; tunc Homerus et Vergilius tam bene de humano genere meriti quam tu et de illis et de omnibus meruisti, quos pluribus notos esse voluisti quam scripserant, multum tecum morentur; tutum id erit omne tempus, quod illis tuendum commiseris".

${ }^{34}$ Trist. 3, 14, 1. Cf. PIERINI, Rita Degl'Innocenti. Tra Ovidio e Seneca, op. cit., 1990, p. 115.

${ }^{35}$ Ver também Marcial, 5.5.1, quando trata de Sexto, liberto de Domiciano: Sexte, Palatinae cultor facunde Minervae. Cf. PIERINI, Rita Degl'Innocenti. Tra Ovidio e Seneca, op. cit., 1990, p. 115.

${ }^{36}$ Ad Pol. 18.9. No original: "Haec, utcumque potui, longo iam situ obsoleto et hebetato animo composui. Quae si aut parum respondere ingenio tuo aut parum mederi dolori videbuntur, cogita, quam non possit is alienae vacare consolationi, quem sua mala occupatum tenent, et quam non facile latina ei homini verba succurrant, quem barbarorum inconditus et barbaris quoque humanioribus gravis fremitus circumsonat".
} 
Ênfase é conferida ao papel do destino (fatum) e da fortuna (fortuna), a ponto de o Ad Polybium se sobressair nesse ponto em relação às outras cartas consolatórias escritas por Sêneca. Logo no início, lemos:

Por muito tempo podemos acusar o destino; mudá-lo, não: permanece duro e inexorável. Ninguém o move com insultos, ninguém com choro, ninguém com razões. Jamais se abstém ou afasta algo de alguém. Assim, poupemos as lágrimas inúteis; afinal, mais facilmente essa dor nos levará aos que perdemos do que os trará de volta a nós. ${ }^{37}$

Sêneca, mais adiante, contudo, confere um tom positivo ao destino, pois ele acaba livrando o homem, com a morte, das amarras terrenas, conduzindo-o a uma situação melhor:

Acredita em mim, aquele para quem a sorte [fortuna] é supérflua é mais feliz do que aquele por quem foi alcançada. [...] Finalmente livre, finalmente, seguro, finalmente eterno está. Tem César, todos os filhos dele e a ti sãos e salvos, além dos irmãos comuns; antes que a sorte mudasse algo com respeito às suas graças, deixou-a ainda de pé e empilhando dons com mão cheia. Usufrui agora de um céu aberto e livre: elevou-se de um lugar humilde e rebaixado para aquele, qualquer que seja ele, que recebe no seio ditoso as almas soltas das amarras, e agora vaga ali livremente e enxerga todos os bens da natureza das coisas com o maior prazer. ${ }^{38}$

Com essa apresentação da situação do irmão de Políbio como "livre", Sêneca acaba criando um contraste com a posição do próprio destinatário, igualmente determinada pela sorte (fortuna), mas agora como "escravo":

[...] um destino privilegiado é uma grande escravidão [magna servitus est magna fortuna]. Nada te é permitido fazer a teu bel-prazer: tantos milhares de homens a ouvir, tantos requerimentos a ordenar; tamanha soma de negócios afluindo do mundo todo deve ser desemaranhada para que possa fazer-se ver em ordem pelo maior príncipe. Não te é permitido, digo, chorar: para que possas ouvir muitos lamentosos, para que possas

\footnotetext{
${ }^{37}$ Ad Pol. 4.1. No original: "Diutius accusare fata possumus, mutare non possumus: stant dura et inexorabilia. Nemo illa convicio, nemo fletu, nemo causa movet; nihil umquam ulli parcunt nec remittunt. Proinde parcamus lacrimis nihil proficientibus; facilius enim nos inferis dolor iste adiciet quam illos nobis reducet".

${ }^{38}$ Ad Pol. 9.5 e 7-8. No original: "Mihi crede, is beatior est, cui fortuna supervacua est, quam is, cui parata est. [...] Tandem liber, tandem tutus, tandem aeternus est. Superstitem Caesarem omnemque eius prolem, superstitem te cum communibus habet fratribus; antequam quicquam ex suo favore fortuna mutaret, stantem adhuc illam et munera plena manu congerentem reliquit. Fruitur nunc aperto et libero caelo, ex humili atque depresso in eum emicuit locum, quisquis ille est, qui solutas vinculis animas beato recipit sinu, et nunc libere illic vagatur omniaque rerum naturae bona cum summa voluptate perspicit".
} 
ocupar-te das lágrimas dos que correm riscos e desejam alcançar a misericórdia do mais brando César, as tuas devem estar secas. ${ }^{39}$

Essa oposição entre liberdade e escravidão é comum no estoicismo e, no caso de Sêneca, algumas vezes ilustrada com exemplos de escravos que se entregam à morte como forma de afirmar sua liberdade moral. ${ }^{40}$ Porém, pode-se aventar a possibilidade de que teríamos aqui uma dupla leitura, um exemplo da ambivalência da linguagem estoica que oscila entre o significado literal de um termo, relacionado aos valores convencionais romanos, e aquele mais propriamente estoico. Liberdade e escravidão podem conter, assim, um duplo sentido, estoico e tradicional, do mesmo modo que Sêneca serve-se da expressão bonus vir, que pode significar tanto um homem bom como o sábio estoico.

Essa ambivalência do discurso de Sêneca é relevante para a compreensão do retrato de Políbio. Em contraste com as outras consolações, que escrevera a Márcia e a sua mãe, Hélvia, a despeito da presença dos mesmos temas - a fugacidade da vida, a inevitabilidade da morte e a impossibilidade de uma posse constante, seja de bens materiais, seja dos entes queridos -, o conselho que Sêneca dirige a essas mulheres e a Políbio diverge profundamente. Enquanto as primeiras devem buscar apoio e consolo na estrutura familiar restante, em especial nos filhos homens, capazes de manter a continuidade da família e a transmissão do patrimônio, Políbio, apesar de ter esposa e filho, deve apegar-se ao imperador, como se fossem indissociáveis um do outro:

Quando quiseres esquecer tudo, pensa em César: vê quanta lealdade, quanto trabalho deves à sua bondade em teu favor [Vide, quantam huius in te indulgentiae fidem, quantam industriam debeas]; entenderás que não te é permitido abater-te mais do que aquele, em cujos ombros o mundo se apoia, se se acredita em fábulas. Mesmo ao próprio César, a quem tudo é lícito, por este motivo muitas coisas não são permitidas: a sua vigília protege o sono de todos, a sua fadiga, o ócio de todos; a sua atividade, os prazeres, o seu trabalho, o repouso. Desde o dia em que César se dedicou ao mundo, se privou de si mesmo e, como os astros, que desenvolvem seu curso sem cessar, nunca lhe é

\footnotetext{
39 Ad Pol. 6.4-5. No original: "magna servitus est magna fortuna. Non licet tibi quicquam arbitrio tuo facere: audienda sunt tot hominum milia, tot disponendi libelli; tantus rerum ex orbe toto coeuntium congestus, ut possit per ordinem suum principis maximi animo subici, exigendus est. Non licet tibi, inquam, flere: ut multos flentes audire possis, ut periclitantium et ad misericordiam mitissimi Caesaris pervenire cupientium lacrimae tibi sint curae, tuae assiccandae sunt".

${ }^{40}$ Ep. 4.4; 70.20 e 77.14-15.
} 
permitido descansar nem fazer qualquer coisa para si mesmo. E assim, de certo modo, essa mesma necessidade se aplica a ti. ${ }^{41}$

Os retratos de Políbio e Cláudio aqui confluem por conta da relação específica que imperador e liberto firmam entre si. A relação de ambos é exemplo de que um grande poder corresponde a uma grande escravidão, tema estoico também presente no De clementia, e a existência do súdito se confunde com a do monarca. Esta questão não passou despercebida pela crítica moderna. Liz Gloyn, por exemplo, lê a figura de Cláudio como emblemática de um deus estoico, que orienta Políbio no caminho da razão. ${ }^{42}$ Nessa mesma linha, embora mais voltada para o campo da ideologia política, há a interpretação avançada por Siegmar Döpp, para quem Sêneca descreve Cláudio de acordo com suas expectativas de começo de governo: com um poder soberano, centrado na clemência e influenciando até mesmo a esfera emotiva e privada dos súditos, tal como ocorre com Políbio. ${ }^{43}$

É certo que temos o retrato de Políbio como um sábio estoico, como um literato, que Sêneca desenha para reforçar seu próprio retrato de sábio exilado, que sofreu nas mãos da Fortuna e espera a clemência imperial. Sêneca e Políbio estão em certa situação de igualdade, pois dependem do imperador para superar suas perdas. No que tange especificamente à passagem anteriormente citada, essa chave de leitura conforma os comentários modernos sobre o Ad Polybium. Assim, centrando-se no termo indulgentia, Thomas Kurth salienta que Sêneca o utiliza num sentido intermediário entre retribuição a um beneficium imperial e seu sentido mais constitucional, que será comum no século II, relacionado à anistia em questões criminais. ${ }^{44}$

Entretanto, penso que podemos ir um pouco mais além de uma leitura filosófica ou político-ideológica da Consolação. Isso porque tais interpretações fazem que passe desapercebida a própria conotação escravista da passagem: “Quando quiseres esquecer tudo, pensa em César: vê quanta lealdade (fides),

\footnotetext{
${ }^{41}$ Ad Pol. 7.1-3. No original: "Cum voles omnium rerum oblivisci, Caesarem cogita: vide, quantam huius in te indulgentiae fidem, quantam industriam debeas; intelleges non magis tibi incurvari licere quam illi, si quis modo est fabulis traditus, cuius umeris mundus innititur. Caesari quoque ipsi, cui omnia licent, propter hoc ipsum multa non licent: omnium somnos illius vigilia defendit, omnium otium illius labor, omnium delicias illius industria, omnium vacationem illius occupatio. Ex quo se Caesar orbi terrarum dedicavit, sibi eripuit, et siderum modo, quae irrequieta semper cursus suos explicant, numquam illi licet subsistere nec quicquam suum facere. Ad quendam itaque modum tibi quoque eadem necessitas iniungitur [...]".

${ }^{42}$ GLOYN, Liz. Show me the way to go home: a reconsideration of Seneca's De consolatione ad Polybium, op. cit., 2014.

${ }^{43}$ DOPP, Siegmar. Claudius in Senecas Trostschift an Polybius, op. cit., 1994.

${ }^{44}$ KURTH, Thomas. Senecas Trostschrift an Polybius: dialog 11. Stuttgart: Teubner, 1994, p. 92.
} 
quanto trabalho (industria) deves à sua bondade em teu favor". Fides e industria são os principais termos utilizados na literatura latina para descrever as qualidades dos libertos e os pré-requisitos para a manumissão de um escravo. ${ }^{45} \mathrm{O}$ tema do liberto ingrato é particularmente presente à época JúlioCláudia, como sabemos pelos testemunhos de Tácito ${ }^{46}$ e Suetônio ${ }^{47}$. O liberto, na Consolação, é representado assim como uma extensão direta do patrono, como se não tivesse uma existência autônoma. Por mais alto que Políbio tenha chegado na casa imperial, obtendo uma função pública, aos olhos de Sêneca nada mais é do que um escravo numa domus.

Essa tensão entre existência pública e privada do liberto encontra expressão num debate no conselho do imperador Nero, em 56, acerca da punição aos libertos ingratos, conforme relatado por Tácito, quando os aristocratas favoráveis à revogação da liberdade argumentaram que

nem seria ofensivo para os libertos manter a liberdade com a mesma reverência com a qual tinham-na obtido. Quanto aos culpados de crimes, estes voltariam à escravidão merecidamente, para que pelo medo se coibissem aqueles que os benefícios não melhoravam. ${ }^{48}$

A proposta contrária, e que obteve apoio do imperador, preconizava que tal punição era injusta, tendo em vista a posição pública atingida pelos libertos:

Dele [do corpo de libertos] provinha a maior parte das tribos, das decúrias, dos auxiliares de magistrados e sacerdotes e dos soldados alistados nas coortes urbanas. E grande parte dos cavaleiros e muitos senadores não tinham outra origem. Caso se separassem os filhos de libertos, o pequeno número dos homens nascidos livres seria evidente. Não fora em vão que os antigos, quando estabeleceram a divisão das ordens, consideraram a liberdade como bem comum. E tinham estabelecido dois meios de a conferir, a fim de dar tempo ao arrependimento ou a um novo benefício. Todos aqueles a quem o patrono não tivesse conferido liberdade com as formalidades legais [vindicta] eram mantidos sob um certo vínculo de escravidão [i.e. os Latinos Junianos ${ }^{49}$ ]. Antes de se

${ }^{45}$ Cf. MOURITSEN, Henrik. The freedman in the Roman world. Cambridge: Cambridge University Press, 2011, p. 51.

${ }^{46}$ Ann. 13.26-27.

${ }^{47}$ Cl. 25.1.

${ }^{48}$ Ann. 13.26.7. No original: "[...] nec grave manu missis per idem obsequium retinendi libertatem, per quod adsecuti sint: at criminum manifestos merito ad servitutem retrahi, ut metu coerceantur, quos beneficia non mutavissent".

${ }^{49}$ BARJA DE QUIROGA, Pedro Lopez. Junian Latins: status and numbers. Athenaeum, Como, vol. 86, n. 1, 1998, p. 145. 
conceder a liberdade era necessário examinar os méritos com vagar, mas não revogar o que fora concedido. ${ }^{50}$

A Consolação a Políbio, portanto, não deixa de expressar conteúdos de embates acerca do controle de escravos e libertos colocados à época JúlioCláudia, na esteira da criação do status de Latinus Junianus.

\section{Conclusão}

A reflexão de Sêneca, que se serve do manancial estoico, consiste numa tentativa de minimizar as consequências jurídicas e sociais da manumissão, ou seja, da liberdade, negando uma efetiva autonomização dos libertos frente às domus a que estão ligados. A manumissão teria, nesse sentido, o objetivo de manter o ex-escravo no círculo privado, reforçando a dependência. Sua libertação, por conseguinte, seria meramente uma continuidade da escravidão.

Embora os estoicos concedessem que corpos escravos podiam ter almas livres - decorrência do paradoxo estoico de que apenas o sábio é livre, enquanto os néscios seriam escravos -, ao tratarem dos libertos, essa ideia não encontrava ressonância. É como se o liberto, por não ter nascido livre ou devido ao período no cativeiro, jamais pudesse alcançar a sabedoria. Esse distanciamento entre libertos e ingênuos remete a determinada relação entre liberdade e escravidão, no sentido de que a produção da liberdade civil, por meio da manumissão, visaria sobretudo a reproduzir a escravidão.

Esse discurso pode ser inclusive relacionado com a cultura material de escravos e libertos em Roma, como expressa nos columbaria das casas aristocráticas da primeira metade do século I d.C., momento em que foram compostas as obras de Sêneca (mas também aquelas de Pérsio e Petrônio, contemporâneos do filósofo, em que encontramos ideologia similar). Estudos de arqueologia e epigrafia apontam que predominam em Roma, ao longo desse período, os enterramentos coletivos de escravos e libertos em columbaria, túmulos coletivos que indicavam a centralidade da domus na organização dos laços de

\footnotetext{
${ }_{50}$ Ann. 13.27.1-7. No original: "Disserebatur contra: paucorum culpam ipsis exitiosam esse debere, nihil universorum iuri derogandum; quippe late fusum id corpus. hinc plerumque tribus decurias, ministeria magistratibus et sacerdotibus, cohortes etiam in urbe conscriptas; et plurimis equitum, plerisque senatoribus non aliunde originem trahi: si separarentur libertini, manifestam fore penuriam ingenuorum. non frustra maiores, cum dignitatem ordinum dividerent, libertatem in communi posuisse. quin et manu mittendi duas species institutas, ut relinqueretur paenitentiae aut novo beneficio locus. Quos vindicta patronus non liberaverit, velut vinclo servitutis attineri. Dispiceret quisque merita tardeque concederet, quod datum non adimeretur".
} 
solidariedade e comunidade do pessoal servil. Já a partir do período flaviano, ocorre um declínio dessa forma de enterramento, passando a preponderar sepulcros individuais de libertos, ou seja, a ligação com a familia servil sofre um enfraquecimento. Trata-se de um fenômeno ainda difícil de se explicar as razões. Carlos Galvão-Sobrinho apresenta a hipótese de que a progressiva hierarquização de libertos e escravos no seio das casas aristocráticas possibilitou a emergência de um grupo diferenciado de libertos, com condições de se destacarem posteriormente dessas casas pelos recursos que acumulavam. ${ }^{51}$

A própria legislação augustana soa como uma tentativa de conter esse grupo ao vincular a propriedade dos libertos manumitidos informalmente a seus patronos. E a filosofia estoica acompanhou esse contexto ao buscar equiparar, no plano moral, os libertos aos "escravos".

\section{Referências bibliográficas}

ANDRÉ, Carlos Ascenso. Trilhos de evasão: estratégia retórica de Sêneca nas consolações ad Helviam e ad Polybium. Humanitas, Coimbra, vol. 47, 1995, p. 593-615.

ANDRÉ, Jean-Marie. L'esclavage sous Néron : statut juridique et condition réelle. In: CROISILLE, Jean-Michel \& FAUCHÈRE, Pierre. Neronia 1977 : Actes du $2^{\circ}$ colloque de la Société Internationale d'Études Néroniennes. Clermont-Ferrand: Adosa, 1982, p. 13-22.

ATKINSON, John. Seneca's Consolatio ad Polybium. Aufstieg und Niedergang der römischen Welt, II.32.2, 1985, p. 860-883.

BARJA DE QUIROGA, Pedro Lopez. Junian Latins: status and numbers. Athenaeum, Como, vol. 86, n. 1, 1998, p. 133-163.

BORBONUS, Dorian. Columbarium tombs and collective identity in Augustan Rome. Cambridge: Cambridge University Press, 2014.

BRIQUEL, Dominique. Petite histoire d'une grande idée : l'ouverture de la citoyenneté aux anciens esclaves, source de la puissance de Rome. Acta Classica, Pretoria, vol. 36, 2000, p. 31-49.

\footnotetext{
${ }^{51}$ GALVÃO-SOBRINHO, Carlos. Feasting the dead together: household burials and the social strategies of slaves and freed persons in the early Principate, op. cit., 2012, p. 148. Na mesma linha, Dorian Borbonus (2014) afirma que a predominância dos columbaria estaria relacionada ao nível de integração, em especial dos libertos, na sociedade romana. Aqueles libertos de primeira geração estariam mais sob o controle dos patronos, embora fossem juridicamente livres. Essa tensão entre liberdade e subordinação era contornada por uma cultura funerária que enfatizava a comunidade como elemento importante da vida desse segmento. Na medida em que, como nota Borbonus (2014, p. 144), os descendentes desses libertos não herdavam esse status legal, a noção de comunidade se enfraquecia e formas mais individualizadas de representação funerária tendiam a emergir, uma situação similar àquela de "populações imigrantes modernas que passariam por uma reversão geracional de identidade cultural e interesses".
} 
BUCKLAND, William. The Roman law of slavery. Cambridge: Cambridge University Press, 1908.

CASSIUS, Dio. Roman History, vol. 2. Translated by Earnest Cary and Herbert B. Foster. Cambridge: Harvard University Press, 1924. (Loeb Classical Library).

DOPP, Siegmar. Claudius in Senecas Trostschift an Polybius. In: STROCKA, Volker (ed.). Die Regierungszeit des Kaiser Claudius (41-54 n. Chr.): Umbruch oder Episode? Mainz: Philipp von Zabern, 1994, p. 295-306.

EDWARDS, Catharine. Free yourself!: slavery, freedom and the self in Seneca's letters. In: BARTSCH, Shadi \& WRAY, David (ed.). Seneca and the self. Cambridge: Cambridge University Press, 2009, p. 139-159.

FANTHAM, Elaine. Dialogues of displacement: Seneca's consolations to Helvia and Polybius. In: GAERTNER, Jan. (ed.). Writing exile: the discourse of displacement in Greco-Roman Antiquity and beyond. Leiden: Brill, 2007, p. 173-192.

FAVERSANI, Fábio. Entre a República e o Império: apontamentos sobre a amplitude desta fronteira. Mare Nostrum, São Paulo, n. 4, 2013, p. 100-111.

GALVÃO-SOBRINHO, Carlos. Feasting the dead together: household burials and the social strategies of slaves and freed persons in the early Principate. In: BELL, Sinclair \& RAMSBY, Teresa (ed.). Free at last!: the impact of freed slaves on the Roman Empire. London: Bristol Classical Press, 2012, p. 130-176.

GARDNER, Jane. The purpose of the Lex Fufia Caninia. Echos du Monde Classique/ Classical Views, Toronto, vol. 35, 1990, p. 21-39.

GARNSEY, Peter. Ideas of slavery from Aristotle to Augustine. Cambridge: Cambridge University Press, 1996.

GLOYN, Liz. Show me the way to go home: a reconsideration of Seneca's De consolatione ad Polybium. American Journal of Philology, Baltimore, vol. 135, n. 3, 2014, p. 451-480.

GRIFFIN, Miriam. Seneca: a philosopher in politics. Oxford: Oxford University Press, 1976.

INWOOD, Brad. Reading Seneca: Stoic philosophy at Rome. Oxford: Oxford University Press, 2005.

JOLY, Fábio Duarte. Libertate opus est: escravidão, manumissão e cidadania à época de Nero (54-68 d.C.). Curitiba: Progressiva, 2010.

KOOPS, Egbert. Masters and freedmen: Junian Latins and the struggle for citizenship. In: DE KLEIJN, Gerda \& BENOIST, Stéphane (ed.). Integration in Rome and in the Roman world: proceedings of the Tenth Workshop of the International Network Impact of Empire (Lille, June 23-25, 2011). Leiden: Brill, 2014, p. 105-126.

KURTH, Thomas. Senecas Trostschrift an Polybius: dialog 11. Stuttgart: Teubner, 1994.

MILLER, Joseph. The problem of slavery as history: a global approach. Yale: Yale University Press, 2012.

MORLEY, Neville. Slavery under the Principate. In: BRADLEY, Keith $\mathcal{E}$ CARTLEDGE, Paul (org.). The Cambridge world history of slavery, vol. 1. Cambridge: Cambridge University Press, 2011, p. 265-286.

MOURITSEN, Henrik. The freedman in the Roman world. Cambridge: Cambridge University Press, 2011. 
OSGOOD, Josiah. Claudius Caesar: image and power in the Early Roman Empire. Cambridge: Cambridge University Press, 2011.

PATTERSON, Orlando. Slavery and social death: a comparative study. Massachusetts: Harvard University Press, 1982.

PIERINI, Rita Degl'Innocenti. Tra Ovidio e Seneca. Bologna: Pàtron Editore, 1990.

ROLLER, Matthew. Constructing autocracy: aristocrats and emperors in Julio-Claudian Rome. Princeton: Princeton University Press, 2001.

SÊNECA. Des bienfaits. Tradução de François Préchac. Paris: Les Belles Lettres, 19261928. 3 vol.

. Dialogues: Consolations. Tradução de René Waltz. Paris: Les Belles Lettres, 1950. Epistulae Morales. Cambridge: Harvard University Press, 1979. 2 vol. (Loeb Classical Library).

. Cartas a Lucílio. Tradução de J. Segurado e Campos. Lisboa: Fundação Calouste Gulbenkian, 1991.

Consolação a Políbio. Tradução de Matheus Trevizam e Ana Araújo Grossi Ribeiro. Belo Horizonte: FALE: UFMG, 2007.

SUETONIUS. De vita Caesarum libri. Stuttgart: Teubner, 1958.

TACITE. Annales. Tradução de Henri Goelzer. Paris: Les Belles Lettres, 1953. 3 vol.

THORSTEINSSON, Runar. Roman Christianity and Roman Stoicism: a comparative study of ancient morality. Cambridge: Cambridge University Press, 2010.

WEAVER, Paul R. C. Repertorium familiae caesarum et libertorum augustorum. Köln: Universität zu Köln, 2005. Disponível em: http://alte-geschichte.phil-fak.uni-koeln. de/500.html. Acesso em: 15/02/2016. 